\title{
Soluble interleukin-18 receptor complex is a novel biomarker in rheumatoid arthritis
}

\author{
Satoko Takei, Tomoaki Hoshino ${ }^{*}$, Kazuko Matsunaga, Yuki Sakazaki, Masanori Sawada, Hanako Oda, \\ Shin-ichi Takenaka, Haruki Imaoka, Takashi Kinoshita, Seiyo Honda, Hiroaki Ida, Taka-aki Fukuda and \\ Hisamichi Aizawa
}

\begin{abstract}
Introduction: There has been no report in the literature of a soluble form of interleukin (IL)-18 receptor $\alpha$ (IL-18R $\alpha$ ). In this study, we evaluated the levels and characteristics of soluble IL-18R $(\mathrm{sIL-18R \alpha )}$ in the sera of patients with rheumatoid arthritis (RA) and compared these results to control populations.

Methods: The sIL-18R $\alpha$ complex was isolated from pooled human blood serum using an anti-IL-18R $\alpha$ monoclonal antibody affinity column. The purified SIL-18R $\alpha$ was then examined using Western blot analysis and used in experiments to evaluate the effects on an IL-18-responsive natural killer (NK) human cell line, NKO. An enzymelinked immunosorbent assay was developed, and sera from 145 patients with RA, 6 patients with adult-onset Still's disease, 31 patients with osteoarthritis (OA), 39 patients with systemic lupus erythematosus (SLE) and 67 controls were tested, along with levels of immunoglobulin $\mathrm{M}$, rheumatoid factor, anticyclic citrullinated peptide antibody, IL-18, IL-13 and interferon (IFN)- $\gamma$. Area under the receiver operating characteristic curve (ROC-AUC) analysis was used to evaluate the diagnostic utility of the sIL-18R $\alpha$ complex.

Results: The isolated IIL-18R $\alpha$ complex can be associated with IL-18 and the soluble form of the IL-18R $\beta$ chain. The sIL$18 R \alpha$ complex bound to the surface to the NKO cell line, antagonized the stimulatory effects of IL-18 and IL-2 on the NKO cell line and inhibited IFN- $\gamma$ production by the cells. The serum levels of slL-18R $\alpha$ complex in RA (186.0 $\pm 33.5 \mathrm{ng} /$ $\mathrm{mL}, n=145)$ and adult-onset Still's disease $(98.2 \pm 8.9 \mathrm{ng} / \mathrm{mL}, n=6)$ were significantly $(P<0.001)$ higher than those in the healthy controls ( $52.3 \pm 8.5 \mathrm{ng} / \mathrm{mL}, n=67), \mathrm{OA}(38.6 \pm 5.4 \mathrm{ng} / \mathrm{mL}, n=31), \mathrm{SLE}(44.6 \pm 3.2 \mathrm{ng} / \mathrm{mL}, n=39)$. The serum level of sIL-18R $\alpha$ complex was not significantly different between RA and adult-onset Still's disease patients. The serum levels of IL-18, IL-13 and IFN- $\gamma$ in the RA patients were significantly $(P<0.01)$ higher than in OA and SLE patients as well as healthy controls. ROC-AUC analysis of the serum concentration of sIL-18R $\alpha$ indicated that it was significantly diagnostic of RA. Moreover, a tumor necrosis factor inhibitor, etanercept, significantly $(P<0.0001)$ decreased levels of sIL-18R $\alpha$ in the sera of 29 RA patients 6 months after treatment.
\end{abstract}

Conclusions: The sIL-18R $\alpha$ complex could be a potentially useful biomarker for the diagnosis of RA.

\section{Introduction}

Interleukin (IL)- $1 \alpha$ and IL- $1 \beta$ have two homologous receptors $I L-1$ receptor 1 , type I (IL-1RI) and IL-1R, type II (IL-1RII). Functional IL-1R is a complex comprising IL-1RI and IL-1 receptor accessory protein (IL-1RAcP) (see reviews in [1-3]). Upon binding of IL-1 $\alpha$ or IL-1 $\beta$, IL-1RI forms a complex with IL-1RAcP

\footnotetext{
* Correspondence: hoshino@med.kurume-u.ac.jp
Division of Respirology, Neurology, and Rheumatology, Department of

* Correspondence: hoshino@med.kurume-u.ac.jp
Division of Respirology, Neurology, and Rheumatology, Department of Medicine, Kurume University School of Medicine, 67 Asahi-machi, Kurume, Fukuoka 830-0011, Japan
}

and initiates a cytosolic signaling cascade (myeloid differentiation primary response protein (MyD88), IL1Rassociated kinase (IRAK) and tumor necrosis factorassociated factor 6 protein (TRAF6), as well as activation of nuclear factor $\kappa \mathrm{B}(\mathrm{NF} \kappa \mathrm{B})$, c-Jun $\mathrm{N}$-terminal kinase (JNK) and p38 mitogen-activated protein kinase (p38 MAPK)). In contrast, $60-\mathrm{kDa}$ IL-1RII functions as a nonsignaling "decoy" receptor. It has been reported that IL-1RI has a soluble form (sIL-1RI) [4], which can be generated by metalloprotease [5]. Soluble IL-1RII (sIL-1RII) is also generated primarily by proteolytic 
cleavage in response to a variety of stimuli and can attenuate excessive IL-1 bioactivity by preferentially binding IL-1 $\beta$. In contrast, soluble IL-1RAcP (sIL$1 R A c P)$ is generated by alternative splicing rather than by ectodomain cleavage. The soluble receptors sIL-1RI, sIL-1RII and sIL-RAcP may attenuate IL-1 signaling [5].

IL-18, a member of the IL-1 family, is well-known to play an important role in T helper 1 (Th1) cell polarization. IL-18 can also act as a cofactor for T helper 2 (Th2) cell development and immunoglobulin (Ig) E production [6-9]. Many lines of evidence indicate that IL-18 plays an important role in the pathogenesis of inflammatory diseases of the bowel, heart and lung [8-12]. The IL-18R belongs to the IL-1R family [1], and the IL-18R complex is composed of the IL-18R $\alpha$ and IL-18R $\beta$ chains. IL-18R $\alpha$ (IL-1R5 or IL-1R-related protein 1 (IL-1Rrp1)) is the extracellular signaling domain $[1,13]$, whereas IL-18R $\beta$ (IL-R7 and accessory protein-like (AcPL) or IL-18R accessory protein (IL-18RAP)) is an adapter molecule [1] in the complex. IL-18R $\alpha$ alone binds IL-18 with low affinity (dissociation constant $\left(K_{\mathrm{d}}\right)$ 20 to $50 \mathrm{nM}$ ), and IL-18R $\beta$ alone cannot bind IL- 18 . However, IL-18R $\alpha$ can bind with high affinity $\left(K_{\mathrm{d}} 0.3\right.$ $\mathrm{nM}$ ) by recruiting IL-18R $\beta$. Upon IL-18's binding to the IL-18R complex, IL-18 signaling uses the same adapter molecules (MyD88, TRAF6 and IRAK) as the IL-1 family cytokines and elicits similar responses (activation of NF $\kappa \mathrm{B}$, JNK and p38 MAPK) [1]. Both the IL-18R $\alpha$ and IL-18R $\beta$ chains are thought to be essential for IL-18-mediated signaling [14,15]. IL-18 binding protein (IL-18BP) is a soluble protein that binds to IL-18 with high affinity $\left(K_{\mathrm{d}} 0.4 \mathrm{nM}\right)$ and exerts neutralizing activity against IL-18 $[1,8,16]$. Another member of the IL-1 family, IL-33, binds to the IL-1R family ST2 (IL-33R $\alpha$ ) and IL-1RAcP (IL-33R $\beta$ ) complex on cell surfaces and induces the production of Th2 cytokines such as IL-4, IL-5 and IL-13 [3]. Soluble ST2 functions as a soluble decoy receptor for IL-33 and blocks IL-33 signaling [17]. These characteristics suggest that the IL-18R $\alpha$ or IL-18 $\beta$ chain may have a soluble form.

Recently, the cytokine milieu of the joint in RA patients has become well-understood, and data from human clinical trials are now available. Therapies designed to block the effects of inflammatory cytokine tumor necrosis factor (TNF) $-\alpha$ and the action of the IL-6 receptor (IL-6R) are well-known to be effective in many RA patients. Rheumatoid subcutaneous nodules have the features of Th1 granulomas, with abundant expression of inflammatory cytokines, including interferon (IFN) $-\gamma$ and IL-18 [8]. The level of IL-18 is reportedly increased in both the serum and rheumatoid synovial fluid, as well as in the bone marrow, of patients with RA, juvenile RA, adult-onset Still's disease and psoriatic arthritis $[8,18,19]$. Moreover, recombinant human IL-18 (rhIL-18) is being actively investigated for its potential efficacy and safety in the treatment of RA. Recent data illustrate the importance of IL-18 in the induction and perpetuation of chronic inflammation in RA patients $[9,19]$.

As yet, no reported study has focused on the sIL-18R $\alpha$ chain. In the present study, we attempted to isolate and characterize the human sIL-18R $\alpha$ complex from human serum. We also found that serum levels of the complex in RA patients were significantly higher than those in healthy controls. Our findings suggest that the sIL-18R $\alpha$ complex could be a potentially useful biomarker for the diagnosis of RA.

\section{Materials and methods Subjects}

One-hundred forty-five patients (24 males and 121 females) diagnosed with RA were studied. The diagnosis of RA was based on the criteria of the American College of Rheumatology (ACR) [20]. Joint damage was assessed by a radiologist on the basis of the Steinbrocker global score (classes I to IV). The Steinbrocker functional classification was used by the physician to rate the extent of physical disability on a four-point scale ranging from class I, "complete functional capacity to carry out all usual duties without handicap," to class IV, "largely or wholly incapacitated, and bedridden or confined to a wheelchair" [21]. The rheumatoid arthritis 28-joint Disease Activity Score (DAS28) based on C-reactive protein (CRP) level and the DAS28 based on erythrocyte sedimentation rate (ESR), as well as the Health Assessment Questionnaire (HAQ) score, were calculated as previously reported $[22,23]$. All patients had been consecutively monitored from 2005 to 2010 at Kurume University Hospital (Kurume, Japan). Serum samples were also obtained from 67 age-matched healthy volunteers, who served as controls. Laboratory data, including white blood cell (WBC) count, CRP level, IgM rheumatoid factor (RF) and anticyclic citrullinated peptide (CCP) antibody levels were examined at Kurume University Hospital as reported previously [24]. Six patients with adult-onset Still's disease were diagnosed according to criteria published by Yamaguchi et al. [25]. Thirty-one patients with osteoarthritis (OA), and 39 patients with systemic lupus erythematosus (SLE) were diagnosed as previously reported [26,27]. The details of these subjects are shown in Table 1 . Sample collection and all procedures were approved by the ethics committee of Kurume University in accordance with the ethical standards of the Helsinki Declaration of 1975. Informed consent was obtained from all patients and healthy volunteers. 
Table 1 Characteristics of rheumatoid arthritis (RA) patients and control participants ${ }^{\mathrm{a}}$

\begin{tabular}{|c|c|c|c|c|c|}
\hline Participant characteristics & Control $(n=67)$ & RA $(n=145)$ & $\operatorname{AOSD}(n=6)$ & OA $(n=31)$ & SLE $(n=39)$ \\
\hline$\overline{M e a n}$ age, yr $( \pm$ SEM $)$ & $60.7 \pm 2.1$ & $56.7 \pm 1.2$ & $54.3 \pm 9.9$ & $76.3 \pm 1.5^{\mathrm{b}}$ & $38.8 \pm 2.1^{b}$ \\
\hline \multicolumn{6}{|l|}{ Sex, $n$} \\
\hline Male & 40 & $24^{\mathrm{b}}$ & $1^{\mathrm{b}}$ & $6^{\mathrm{b}}$ & $6^{b}$ \\
\hline Female & 27 & 121 & 5 & 25 & 33 \\
\hline \multicolumn{6}{|l|}{ Smoking status, $n$} \\
\hline Nonsmoker & 37 & 32 & 1 & 0 & 0 \\
\hline Smoker & 30 & 12 & 0 & 0 & 0 \\
\hline Unknown & 0 & 101 & 5 & 31 & 39 \\
\hline \multicolumn{6}{|l|}{ Joint damage ${ }^{c}, n$} \\
\hline 1 & ND & 42 & ND & ND & ND \\
\hline$\|$ & ND & 47 & ND & ND & ND \\
\hline III & ND & 20 & ND & ND & ND \\
\hline IV & ND & 36 & ND & ND & ND \\
\hline \multicolumn{6}{|l|}{ Functional classification ${ }^{d}, n$} \\
\hline I & ND & 24 & ND & ND & ND \\
\hline$\|$ & ND & 92 & ND & ND & ND \\
\hline III & ND & 29 & ND & ND & ND \\
\hline IV & ND & 0 & ND & ND & ND \\
\hline Mean DAS28 (CRP) ( \pm SEM) & ND & $4.3 \pm 0.1$ & ND & ND & ND \\
\hline Mean DAS28 (ESR) ( \pm SEM) & ND & $4.9 \pm 0.1$ & ND & ND & ND \\
\hline Mean HAQ ( \pm SEM) & ND & $5.8 \pm 0.7$ & ND & ND & ND \\
\hline Mean WBC (cell count/ML) ( \pm SEM) & ND & $7,307.3 \pm 211.0$ & $8,950.0 \pm 533.1$ & $5,134.7 \pm 304.8$ & ND \\
\hline Mean CRP level, mg/dL ( \pm SEM) & ND & $2.27 \pm 0.22$ & $2.15 \pm 1.14$ & $0.08 \pm 0.02$ & ND \\
\hline Mean ESR, mm/hour ( \pm SEM) & ND & $45.0 \pm 2.7$ & $40.3 \pm 18.6$ & ND & ND \\
\hline RF-positive $^{d}, n(\%)$ & $2 / 64(3.1 \%)$ & 106/145 (73.1\%) & 0/6 (0\%) & $2 / 30(6.7 \%)$ & $2 / 39(5.1 \%)$ \\
\hline Mean $\mathrm{RF}, \mathrm{U} / \mathrm{mL}( \pm$ SEM) & $3.7 \pm 1.3$ & $158.0 \pm 20.9^{b}$ & $4.8 \pm 2.7$ & $5.4 \pm 1.3^{b}$ & $3.8 \pm 1.0$ \\
\hline CCP-positive $^{\mathrm{e}}, n(\%)$ & 0/59 (0\%) & $121 / 145(83.4 \%)$ & $1 / 6(16.7 \%)$ & 0/30 (0\%) & $3 / 39(7.7 \%)$ \\
\hline Mean CCP, U/mL ( \pm SEM) & & $0.3 \pm 0.1$ & $261.5 \pm 27.2^{b}$ & $22.5 \pm 22.3$ & $0.5 \pm 0.1^{b}$ \\
\hline PSL, $n(\%)$ & ND & $89 / 145(61.4 \%)$ & ND & ND & ND \\
\hline Mean dose, mg/day ( \pm SEM) & ND & $5.91 \pm 0.32$ & ND & ND & ND \\
\hline MTX, $n(\%)$ & ND & $58 / 145(40.0 \%)$ & ND & ND & ND \\
\hline Mean dose, mg/week ( \pm SEM) & ND & $6.87 \pm 0.34$ & ND & ND & ND \\
\hline DMARDs ${ }^{f}, n(\%)$ & ND & $117 / 145(80.7 \%)$ & ND & ND & ND \\
\hline
\end{tabular}

${ }^{\mathrm{a}} \mathrm{RA}=$ rheumatoid arthritis; AOSD = adult-onset Still's disease; OA = osteoarthritis; SLE = systemic lupus erythematosus; DAS28 = 28-joint Disease Activity Score; $\mathrm{HAQ}=$ Health Assessment Questionnaire; $\mathrm{WBC}=$ white blood cell; $\mathrm{CRP}=\mathrm{C}$-reactive protein; $\mathrm{ESR}=$ erythrocyte sedimentation rate; $\mathrm{RF}=$ rheumatoid factor; $\mathrm{CCP}=$ anticyclic citrullinated peptide antibody; PSL = prednisolone; MTX = methotrexate; DMARDs = disease-modifying antirheumatic drugs; ${ }^{\mathrm{b}} \mathrm{P}<0.05$ vs. healthy controls; 'Steinbrocker global score (I to IV) [21]; 'Steinbrocker functional classification was used, ranging from class I, "complete functional capacity to carry out all usual duties without handicaps," to class IV, "largely or wholly incapacitated with (the person) bedridden or confined to wheelchair" [21]; "cutoff serum concentration of the immunoglobulin $\mathrm{M}$ rheumatoid factor (RF) is 20 units/mL; ${ }^{e}$ cutoff serum concentration of the anti-CCP antibody is $4.5 \mathrm{U} / \mathrm{mL}$; ${ }^{f}$ none of RA patients were treated with tumor necrosis factor $\alpha$ inhibitor at this point.

\section{Reagents}

rhIL-18 (catalog no. B003-5) was purchased from MBL (Nagoya, Japan). rhIL-18R $\alpha$ (IL-1 R5) or Fc chimera (catalog no. 816-LR), mouse antihuman IL-18R $\alpha$ monoclonal antibody (mAb) (clone 70625; catalog no. MAB840) and mouse antihuman IL-18R $\beta$ mAb (clone 132016, catalog no. MAB1181; and clone 132029, catalog no. MAB118) were purchased from R\&D Systems, Inc. (Minneapolis, MN, USA). Rabbit antihuman IL- $18 R \alpha$ polyclonal antibody (pAb) [28] was kindly provided by Dr Tsukasa Seya (Hokkaido University, Sapporo, Japan). Antihuman-IL-18 mAb (clone 8 (IgG2a)) was kindly provided by
Dr Do-Young Yoon (Laboratory of Cellular Biology, Korea Research Institute of Bioscience and Biotechnology, Taejon, Korea [29]). Antihuman-IL-18R $\alpha$ mAb (H44 (IgG1)) was established in our laboratory [30] and is commercially available from BD Pharmingen (San Diego, CA, USA), eBioscience (San Diego, CA, USA), BioLegend (San Diego, CA, USA) and Serotec (Oxford, UK).

\section{Purification of soluble human interleukin-18 receptor $\alpha$ complex from human blood serum}

Mouse antihuman IL-18R $\alpha$ mAb H44 was used on an anti-IL-18R $\alpha \mathrm{mAb}$ affinity column to isolate the complex. 
The H44 hybridoma cell line was cultured in serum-free medium (GIT; Wako Pure Chemical Industries, Ltd., Osaka, Japan). Proteins in cell-free culture supernatants were precipitated with ammonium sulfate and then further purified using a protein G column (GE Healthcare, Tokyo, Japan) as reported previously [31]. This purified H44 mAb was coupled to a HiTrap NHS-activated HP column (GE Healthcare) in accordance with the manufacturer's protocol. Samples of pooled human blood serum were then applied to this affinity column. Phosphate buffer $(10 \mathrm{mM}$, $\mathrm{pH}$ 6.8) was used as the binding buffer, $10 \mathrm{mM}$ phosphate buffer plus $50 \mathrm{mM} \mathrm{NaCl}$ ( $\mathrm{pH}$ 6.8) was used as the washing buffer, $100 \mathrm{mM}$ glycine buffer ( $\mathrm{pH} 2.5$ ) was used as the elution buffer and $1 \mathrm{M}$ phosphate buffer ( $\mathrm{pH}$ 8.0) was used as the neutralization buffer. All buffers were filtered through a $0.45-\mu \mathrm{m}$ filter (Millipore, Tokyo, Japan) before the experiments. Serum samples were diluted twofold with the binding buffer, filtered through a $0.45-\mu \mathrm{m}$ filter (Millipore) and applied to an antihuman IL-18R $\alpha$ mAb affinity column that had been equilibrated beforehand with the binding buffer. The affinity column was washed with the washing buffer. The elution buffer was then allowed to flow through the column, and every 1-mL sample was collected into a test tube containing $50 \mu \mathrm{L}$ of neutralization buffer (fractions collected were denoted in numerical order as fractions 1, 2, 3 and so on), with the fractions being monitored with UV radiation at $280 \mathrm{~nm}$. The collected fractions were dialyzed against distilled $\mathrm{H}_{2} \mathrm{O}$ (Otsuka Pharmaceutical Co., Ltd., Tokushima, Japan) in the presence of $1 \mathrm{mM}$ phenylmethanesulfonyl fluoride (Sigma) at $4^{\circ} \mathrm{C}$. Purified hIL-18R $\alpha$ complex was concentrated using Centricon centrifugal filters (Millipore), and all of the samples and buffers were then kept at $4^{\circ} \mathrm{C}$.

\section{Establishment of enzyme-linked immunosorbent assay system for measurement of serum soluble human interleukin-18 receptor $\alpha$ complex}

H44 mouse antihuman IL-18R $\alpha$ primary mAb dissolved at $4 \mu \mathrm{g} / \mathrm{mL}$ in phosphate-buffered saline (PBS) was dispensed into enzyme-linked immunosorbent assay (ELISA) plates (Nunc, Tokyo, Japan) in aliquots of $100 \mu \mathrm{L} /$ well and left undisturbed overnight at $4^{\circ} \mathrm{C}$ to allow it to become immobilized. The plates were then washed twice with $200 \mu \mathrm{L}$ of PBS buffer containing $0.5 \%$ Tween 20, and $200 \mu \mathrm{L} /$ well of $10 \%$ Block Ace blocking solution (Dainippon Sumitomo Pharma Co., Ltd., Osaka, Japan) were added and left for at least 2 hours at room temperature to prevent nonspecific adhesion of the secondary antibody to the plates. The plates were then washed again twice with $200 \mu \mathrm{L}$ of PBS buffer containing $0.5 \%$ Tween 20 . Human blood serum samples were then aliquoted at $100 \mu \mathrm{L} /$ well. rhIL-18R $\alpha$ protein (R\&D Systems, Inc.) diluted to 400, 200, 100, 50, 25, 12.5 and $6.25 \mathrm{ng} / \mathrm{mL}$ was used as the standard for the human
sIL-18R $\alpha$ complex ELISA system. After 2 hours of incubation at room temperature, each well was washed three times with $200 \mu \mathrm{l}$ of PBS buffer containing $0.5 \%$ Tween 20. Next, $2 \mu \mathrm{g} / \mathrm{mL}$ biotin-labeled rabbit antihuman IL-18R $\alpha$ secondary pAb was dispensed at $100 \mu \mathrm{L} /$ well, followed by incubation for 90 minutes at room temperature, and then each well was washed four times with $200 \mu \mathrm{l}$ of PBS buffer containing 0.5\% Tween 20. This was followed by addition of $100 \mu \mathrm{L}$ of $0.5 \mu \mathrm{g} / \mathrm{mL}$ streptavidin-bound horseradish peroxidase (Upstate, Tokyo, Japan) to each well, and the plates were left undisturbed for 30 minutes at room temperature. Each well was then washed five times with $200 \mu \mathrm{L}$ of PBS buffer containing 0.5\% Tween 20. 2,2'-Azinobis [3-ethylbenzothiazoline-6sulfonic acid]-diammonium salt (ELISA POD Substrate A.B.T.S. kit; Nakarai, Kyoto, Japan) was then added at $100 \mu \mathrm{l} /$ well, and the plates were left undisturbed for 30 minutes at room temperature, followed by addition of a stop solution at $100 \mu \mathrm{L} /$ well to stop the enzyme reaction. The amounts of the sIL-18R $\alpha$ complex protein were determined by measuring the absorbance at $450 \mathrm{~nm}$ in comparison with the standard rhIL-18R $\alpha$ protein sample. The limit of sensitivity of this ELISA system was $<5 \mathrm{ng} / \mathrm{mL}$.

\section{Sodium dodecyl sulfate-polyacrylamide gel electrophoresis and Western blot analysis}

SDS-polyacrylamide gel electrophoresis (PAGE) was performed using premade $10 \%$ to $20 \%$ or $15 \%$ to $25 \%$ polyacrylamide gel (Multigel II Mini; Dai-ichi Kagaku Yakuhin, Tokyo, Japan). The gel was stained with Coomassie Brilliant Blue (CBB) or assessed using Western blot analysis as described in our previous reports [30,32]. MagicMark ${ }^{\mathrm{TM}}$ Western Standard (Invitrogen, Carlsbad, CA, USA) was used for protein band standardization.

\section{Cytokine enzyme-linked immunosorbent assays}

Levels of mature IL-18, IL-13 and IFN- $\gamma$ in serum were measured using ELISA kits (IL-18: MBL, Nagoya, Japan; IL-13 and IFN- $\gamma$ : R\&D Systems, Inc.). The limits of sensitivity of these ELISA kits were $12.5 \mathrm{pg} / \mathrm{mL}, 32 \mathrm{pg} / \mathrm{mL}$ and $8 \mathrm{pg} / \mathrm{mL}$, respectively.

\section{Flow cytometric analysis}

The purified sIL-18R $\alpha$ complex protein and H44 mAb were labeled with biotin as reported previously [31]. Cells were incubated with $2 \mu \mathrm{g}$ of biotinylated control mouse IgG1 (Caltag, Burlingame, CA, USA), $2 \mu \mathrm{g}$ of biotinylated anti-IL-18R $\alpha$ mAb H44 (mouse IgG1) or $10 \mu \mathrm{g}$ of biotinylated anti-IL-18R $\alpha$ complex protein at $4^{\circ} \mathrm{C}$, then washed with PBS and incubated with streptavidin-PE (BD Pharmingen), followed by flow cytometric analysis as reported previously [12]. 
Interferon- $\gamma$ production inhibition assay using a human interleukin-18-responsive natural killer cell line

We used the hIL-18-responsive human natural killer (NK) cell line NK0, a subclone of the original NK92 cell line. Using NKO cells, we performed IFN- $\gamma$ production inhibition assay in vitro as reported previously [29,30]. Briefly, NK0 cells were washed three times and cultured in RPMI 1640 medium with 10\% fetal calf serum (FCS) for 18 hours. The cells were then washed once, suspended at $5 \times 10^{5}$ cells $/ \mathrm{mL}$ in RPMI 1640 medium with $10 \%$ FCS and pretreated with sIL-18R $\alpha$ complex $(0.01$ to $30 \mu \mathrm{g} / \mathrm{mL}$ ) for 10 minutes at room temperature. The cells were then treated with rhIL-2 $(50 \mathrm{IU} / \mathrm{mL})$ plus rhIL-18 (50 ng/mL) for 18 hours. Production of human IFN $-\gamma$ in the supernatants was analyzed using ELISA kits (R\&D Systems, Inc.).

\section{Statistical analysis}

Data are presented as means \pm standard errors of the mean (SEM). Differences between the RA patients and the controls were analyzed by using the Wilcoxon ranksum test. The sensitivity and specificity for the diagnosis of RA were analyzed using area under the receiver operating characteristic curve (ROC-AUC) analysis generated by logistic regression as reported previously [33]. Statistical analysis was performed using the JMP 7.0.1 software package (SAS Institute, Japan, Tokyo, Japan). Differences were considered significant at $P<0.05$.

\section{Results}

Isolation and characterization of soluble human interleukin-18 receptor $\alpha$ complex from human sera

To determine whether the human sIL-18R $\alpha$ complex is present in the sera of healthy individuals, we prepared an anti-IL-18R $\alpha \mathrm{mAb}$ affinity column to isolate the complex using mouse antihuman IL-18R $\alpha \mathrm{H} 44 \mathrm{mAb}$ [30]. Pooled samples of human blood serum were applied to this affinity column as described in Materials and methods. The elution buffer was allowed to flow through the column and was collected in 1-mL fractions. We then measured the levels of sIL-18R $\alpha$ complex in these fractions using a newly developed sandwich ELISA system. The concentrations of sIL$18 \mathrm{R} \alpha$ complex in these fractions were $<100,1,797$, $1,778,1,259,293,<100,<100$ and $<100 \mathrm{ng} / \mathrm{mL}$, respectively. SDS-PAGE followed by CBB staining showed that the isolated sIL-18R $\alpha$ complex exhibited one major band of approximately $50 \mathrm{kDa}$ and other bands of approximately 60 to 80,30 and $15 \mathrm{kDa}$ (Figure $1 \mathrm{~A}$ ).

We performed Western blot analysis to confirm that the IL-18R $\alpha$ protein was present in fraction 3 . This step showed that anti-IL-18R $\alpha$ mAb clone 70625 detected a band of approximately $60 \mathrm{kDa}$ among the rhIL-18R $\alpha / \mathrm{Fc}$ chimera proteins (lane 1 in Figure 1B). The antibody detected bands of approximately 50 and $30 \mathrm{kDa}$ in the isolated sIL-18R $\alpha$ complex (lane 2 in Figure 1B), suggesting that the complex had at least two different sIL$18 \mathrm{R} \alpha$ proteins. Upon IL-18 binding, the IL-18R $\alpha$ chain forms a complex with the IL-18R $\beta$ chain on cell surfaces [1]. Therefore, we hypothesized that the sIL-18R $\alpha$ complex associates with IL-18 and sIL-18R $\beta$ proteins, and we investigated this possibility using Western blot analysis. The anti-IL-18 mAb (clone 8) detected a strong band of approximately $30 \mathrm{kDa}$ and a weak band of $50 \mathrm{kDa}$ (Figure 1C). As the IL-18 monomer has a calculated molecular mass of $14 \mathrm{kDa}$ [34], IL-18 associated with the IL-18R $\alpha$ complex could be dimeric. The antiIL-18R $\beta$ mAb (clone 132016) detected bands of approximately 60, 40 and $18 \mathrm{kDa}$ in the isolated sIL-18R $\alpha$ complex (Figure 1D). Furthermore, a hIL-18 ELISA kit detected IL-18 protein in the isolated sIL-18R $\alpha$ complex (data not shown). These results suggest that the human sIL-18R $\alpha$ complex might be associated with dimeric IL-18 and the sIL-18R $\beta$ chain.

\section{Ability of the soluble interleukin-18 receptor $\alpha$ complex to bind to the surface of a natural killer cell line}

We investigated whether the sIL-18R $\alpha$ complex could bind to NKO cells, a cell line that strongly expresses the hIL-18R $\alpha$ and IL-R $\beta$ chains [30,35]. NK0 cells were incubated with $2 \mu \mathrm{g}$ of biotinylated control mouse IgG1, $2 \mu \mathrm{g}$ of biotinylated anti-IL-18R $\alpha \mathrm{mAb} \mathrm{H} 44$ (mouse IgG1), or $10 \mu \mathrm{g}$ of biotinylated anti-IL-18R $\alpha$ complex protein. Figure $2 \mathrm{~A}$ shows the representative staining patterns of NK0 cells. H44 mAb, but not control IgG1, reacted strongly with $\mathrm{NK} 0$ cells as reported previously [30]. sIL-18R $\alpha$ complex protein also reacted strongly with NK0 cells. However, preincubation with excess IL-18R $\alpha$ protein $(80 \mu \mathrm{g})$ eliminated the binding activity of biotinylated IL-18R $\alpha$ complex proteins $(10 \mu \mathrm{g})$ almost completely. These results suggest that the SIL-18R $\alpha$ complex can bind to the surfaces of NKO cells.

\section{Soluble interleukin-18 receptor $\alpha$ complex prevents} interferon- $\gamma$ production by a human natural killer cell line We examined whether the isolated IL-18R $\alpha$ complex protein was able to prevent or increase the production of IFN- $\gamma$ by NK0 cells stimulated in vitro with IL- 2 or IL-18. We reported previously that rhIL-18 proteins synergistically increased the production rhIL-2-induced IFN- $\gamma$ by NK0 cells [30]. Here we found that the sIL-18R $\alpha$ complex protein alone did not induce IFN- $\gamma$ production by NKO cells and did not synergistically induce IFN- $\gamma$ production by NK0 cells stimulated with IL-2 alone or IL-18 alone (data not shown). Therefore, we examined whether the sIL-18R $\alpha$ complex would be able to prevent IFN- $\gamma$ production by NK0 cells stimulated in vitro with IL-2 or IL-18. Interestingly, IFN- $\gamma$ 


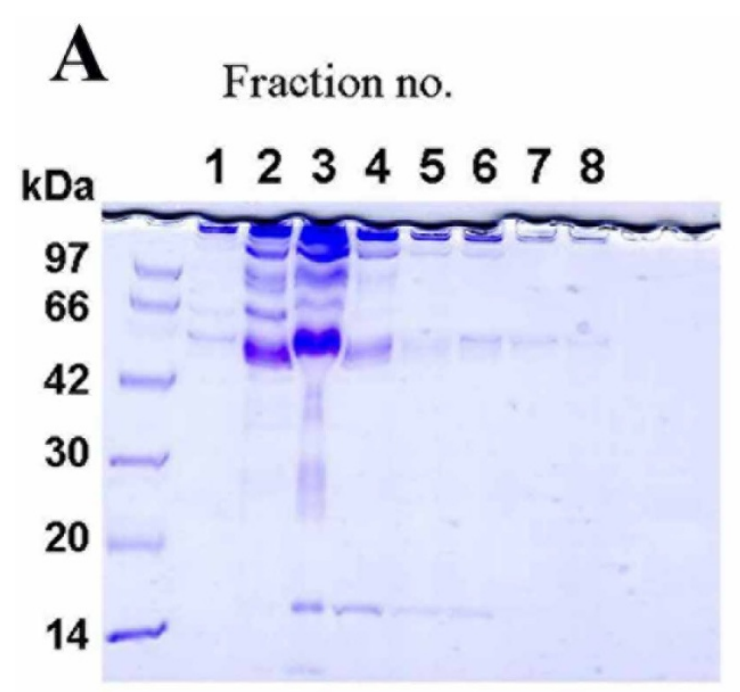

B

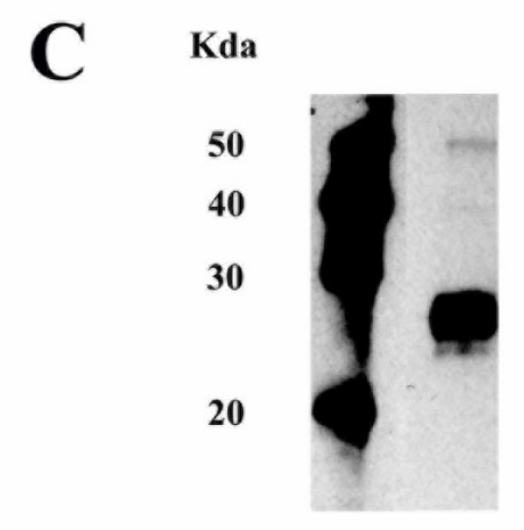

Figure 1 Soluble interleukin-18 receptor $\alpha$ complex is associated with interleukin-18 and the soluble form of the interleukin-18 receptor $\beta$ chain. (A) Sodium dodecyl sulfate (SDS)-polyacrylamide gel electrophoresis of the serum interleukin (IL)-18 receptor $\alpha$ (IL-18R $\alpha$ ) complex. Purified H44 monoclonal antibody (mAb) was coupled to a 5-mL HiTrap NHS-activated HP column (GE Healthcare). Pooled human blood serum $(120 \mathrm{~mL}$ ) was applied to this affinity column. The IL-18Ro complex was eluted with elution buffer at a flow rate of $2 \mathrm{~mL} / \mathrm{minute}$. Every $1 \mathrm{~mL}$ of the elution buffer was collected into a test tube containing $50 \mathrm{~mL}$ of neutralization buffer (collected fractions were denoted in order as fractions 1, 2, 3 and so on). A 10- $\mu \mathrm{L}$ aliquot of every fraction (fractions 1 to 8) was treated with the same volume of sample buffer containing 4\% SDS (Tris-Glycine SDS Sample Buffer (2x); Invitrogen). Electrophoresis was carried out in the presence of $0.1 \%$ SDS, and the gel was stained with Coomassie Brilliant Blue. (B) Western blots of the serum IL-18R $\alpha$ complex using an antihuman IL-18R $\alpha$ mAb are shown. Western blot analysis was performed using antihuman IL-18Ro mAb 70625 (R\&D Systems, Inc.). Lane 1: Western blot showing $1 \mu \mathrm{gg}$ of rhIL-18Ra/ Fc chimera protein (R\&D Systems, Inc.). Lane 2: Western blot showing $5 \mu \mathrm{g}$ of isolated serum IL-18R $\alpha$ complex. (C) Western blot showing serum IL-18Ra complex using an antihuman IL-18 mAb. Western blot analysis was performed using antihuman IL-18 mAb clone 8 with $5 \mu \mathrm{g}$ of isolated serum IL-18R $\alpha$ complex. (D) Western blot showing serum IL-18R $\alpha$ complex using an antihuman IL-18R $\beta$ mAb. Western blot analysis was

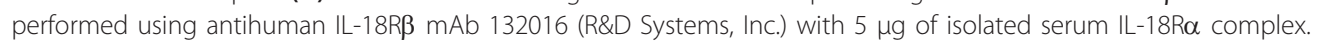

production by NK0 cells stimulated with IL-2 or IL-18 was dose-dependently inhibited by the sIL-18R $\alpha$ complex $(0.003$ to $10 \mu \mathrm{g} / \mathrm{mL}$; approximately $70 \%$ to $80 \%$ inhibition at $10 \mu \mathrm{g} / \mathrm{mL}$ ) (Figure $2 \mathrm{~B}$ ). Thus, the sIL-18R $\alpha$ complex exhibited antagonistic, but not agonistic, activity. In addition, treatment with rhIL-18R $\alpha$ protein (0.1, 1 and $10 \mu \mathrm{g} / \mathrm{mL}$ ) inhibited the production of IFN $-\gamma$ by NK0 cells stimulated with the combination of rhIL-2 $(50 \mathrm{IU} / \mathrm{mL})$ and $\mathrm{rhIL}-18(50 \mathrm{ng} / \mathrm{mL})$ by $0 \%, 2 \%$ and $34 \%$, respectively (data not shown). These results show that the inhibitory effect of the sIL-18R $\alpha$ complex on IFN- $\gamma$ production by NK0 cells stimulated in vitro with IL-18 or IL- 2 is much stronger than that of rhIL-18R $\alpha$ protein.

Increased levels of soluble interleukin-18 receptor $\alpha$ and inflammatory cytokines in sera of rheumatoid arthritis patients

We examined whether the levels of the sIL-18R $\alpha$ complex, IgM RF, anti-CCP antibody, IL-18, IL-13 and IFN- $\gamma$ 


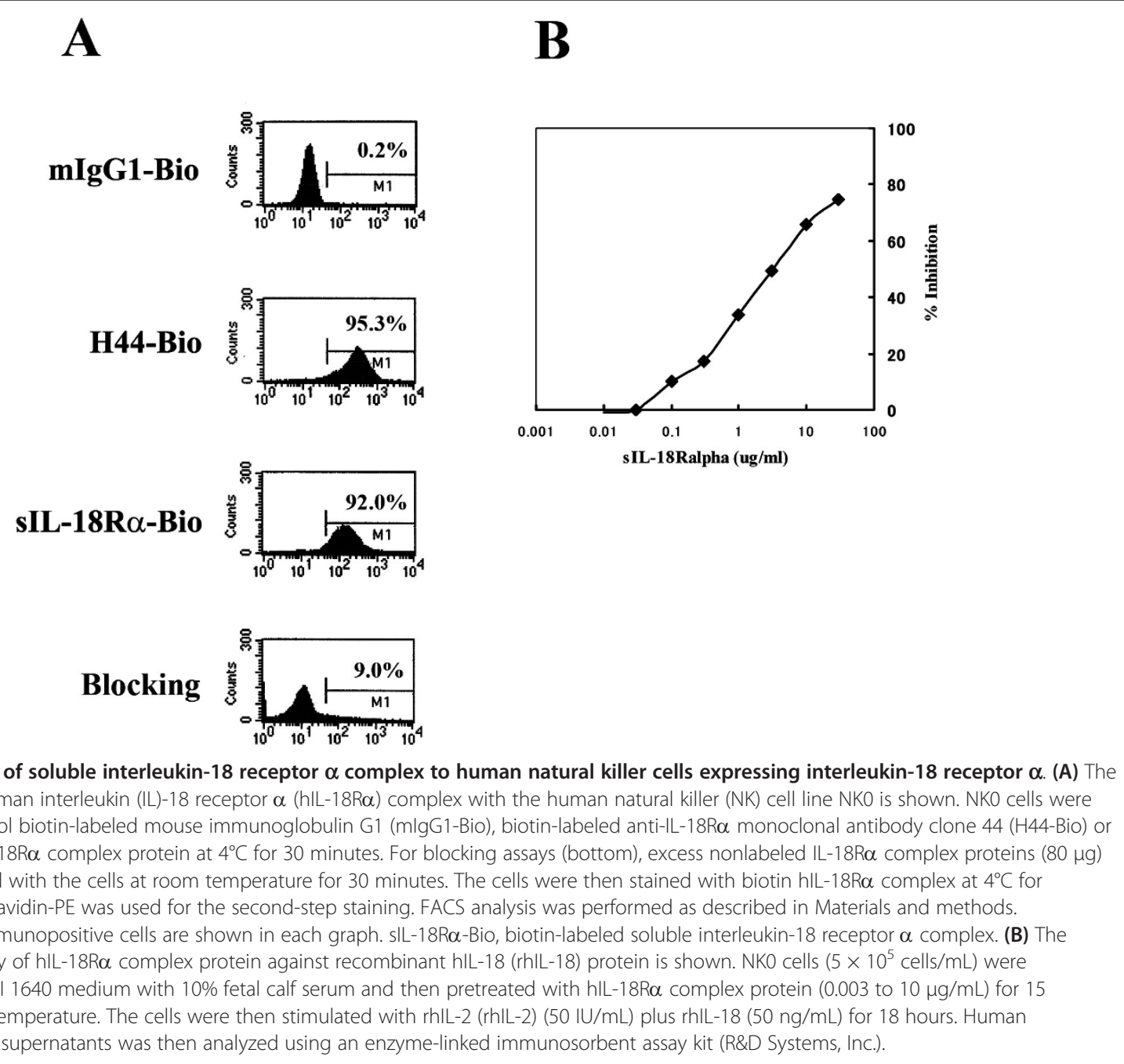

were increased in the sera of RA patients and compared to the levels in patients with inflammatory joint disease (adult-onset Still's disease), a noninflammatory arthritic condition (OA) and an autoimmune disease (SLE) (Figure 3). All of the following data are expressed as means \pm SEM. The serum levels of sIL-18R $\alpha$ complex in RA patients $(186.0 \pm 33.5 \mathrm{ng} / \mathrm{mL}, n=145)$ and adultonset Still's disease $(98.2 \pm 8.9 \mathrm{ng} / \mathrm{mL}, n=6)$ were significantly $(P<0.001)$ higher than those in the healthy controls $(52.3 \pm 8.5 \mathrm{ng} / \mathrm{mL}, n=67)$, OA patients $(38.6 \pm 5.4$ $\mathrm{ng} / \mathrm{mL}, n=31)$ and SLE patients $(44.6 \pm 3.2 \mathrm{ng} / \mathrm{mL}, n=$ 39). The serum levels of sIL-18R $\alpha$ complex were not significantly different between RA patients and adult-onset Still's disease patients. The serum levels of IgM RF and anti-CCP antibody in the RA patients were also significantly $(P<0.0001)$ higher than in the controls (Table 1$)$. However, the serum level of sIL-18R $\alpha$ complex was not significantly associated with that of IgM RF and anti-CCP antibody in RA patients. In addition, sIL-18R $\alpha$ complex was elevated in some RA patients with high serum levels of IgM RF. These results suggest that RF may not influence the detection of sIL-18R $\alpha$ complex. The serum levels of IL-18 in 67 healthy controls, 145 patients with RA, 6 patients with adult-onset Still's disease, 31 patients with OA and 39 patients with SLE were $159.9 \pm 10.9$, $299.4 \pm 16.1,6,566.1 \pm 2,679.7,195.5 \pm 12.8$ and $372.3 \pm$ $32.6 \mathrm{pg} / \mathrm{mL}$, respectively. The serum levels of IL-13 in the same groups were $20.2 \pm 6.9,24.0 \pm 4.5,25.4 \pm 9.2$, $0.5 \pm 0.4$ and $0.2 \pm 0.1 \mathrm{pg} / \mathrm{mL}$, respectively. The serum levels of IFN $-\gamma$ in the same groups were $5.4 \pm 1.0,17.3 \pm$ $3.0,12.2 \pm 9.9,4.1 \pm 2.0$, and $20.4 \pm 11.1 \mathrm{pg} / \mathrm{mL}$, respectively. The serum levels of IL-18, IL-13 and IFN- $\gamma$ in the RA patients were significantly $(P<0.01)$ higher than in OA and SLE patients as well as in healthy controls. There was no significant association between serum levels of sIL-18R $\alpha$ complex and that of IFN- $\gamma$ in RA patients. There was also no significant association between the serum level of sIL-18R $\alpha$ complex and that of 


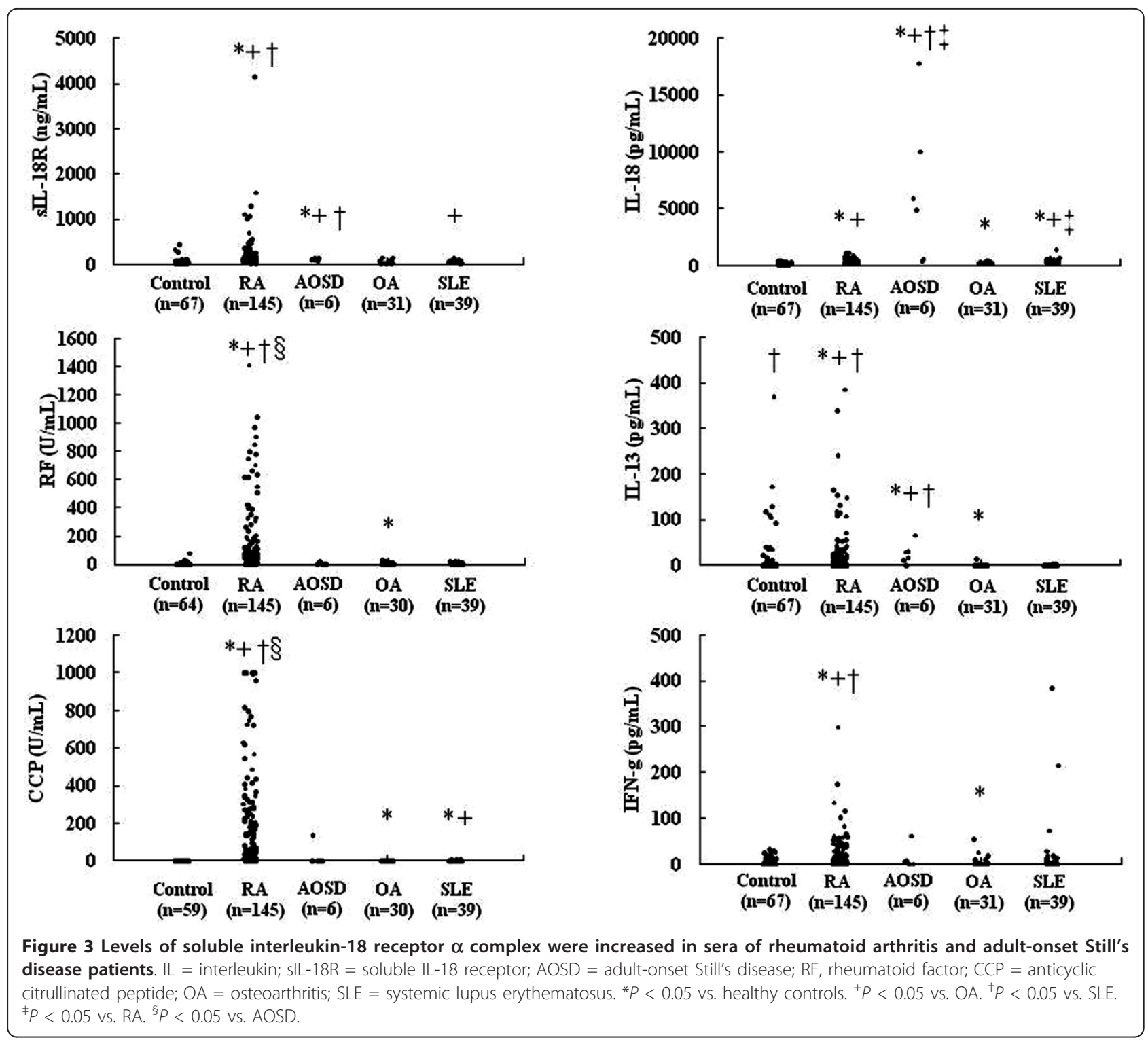

IL-13 or IL-18 in RA patients. In addition, the serum levels of IL-18R $\alpha$ complex, IL-13 and IFN- $\gamma$ were not significantly associated with the Steinbrocker functional classification score, the joint damage score, DAS28 (CRP level), DAS28 (ESR), HAQ value, WBC count, CRP level or smoking status in RA patients. These results suggest that the sIL-18R $\alpha$ complex may not simply be used in the evaluation of joint damage and/or disease activity in RA patients. It is noteworthy that serum levels of IL-18 in patients with adult-onset Still's disease were greatly increased compared to control subjects (Figure 3) as previously reported [18]. The serum levels of IL-18 were significantly associated with HAQ values in RA patients analyzed in this study (data not shown).

Using ROC-AUC analysis, we then evaluated whether the serum levels of the IL-18R $\alpha$ complex, IgM RF, anti-
CCP antibody, IL-18, IL-13 and IFN- $\gamma$ would allow us to discriminate patients with RA from patients with OA or SLE and from healthy controls. The ROC-AUC analysis for the serum level of the IL-18R $\alpha$ complex was 0.826 . At a cutoff point of $63.1 \mathrm{ng} / \mathrm{ml}$, corresponding to the greatest sum of specificity and sensitivity, the specificity was 0.876 and the sensitivity was 0.662 for detection of RA. The ROC-AUC analysis for the serum level of IgM RF was 0.902 . At a cutoff point of $19 \mathrm{U} / \mathrm{mL}$, the specificity was 0.955 and the sensitivity was 0.752 . The ROCAUC analysis for the serum level of anti-CCP antibody was 0.921 . At a cutoff point of $6.5 \mathrm{U} / \mathrm{mL}$, the specificity was 0.992 and the sensitivity was 0.828 (Figure 4). The ROC-AUC analysis for the serum IL-18 level was 0.626. At a cutoff value of $171.2 \mathrm{pg} / \mathrm{mL}$, the specificity was 0.409 and the sensitivity was 0.835 . The ROC-AUC 

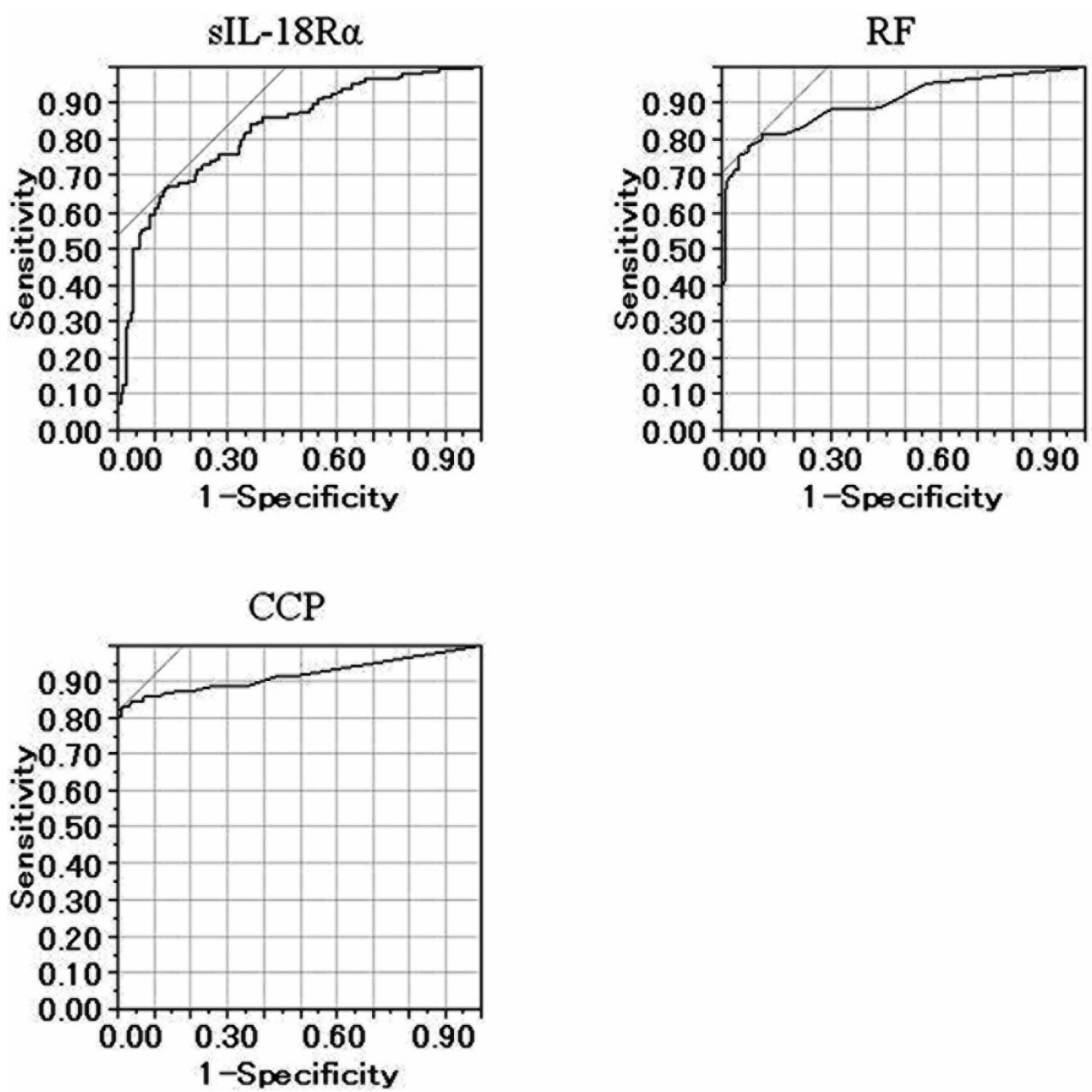

Figure 4 Area under the receiver operating characteristic curves for detection of rheumatoid arthritis by reference to the level of serum soluble interleukin-18 receptor $\alpha$ complex, immunoglobulin $M$ rheumatoid factor, and anticyclic citrullinated peptide antibody. The area under the receiver operating characteristic curve (ROC-AUC) for the soluble interleukin-18 receptor $\alpha$ (sIL-18R $\alpha$ ) complex was 0.826 . At a cutoff point of $63.1 \mathrm{ng} / \mathrm{ml}$, corresponding to the greatest sum of specificity and sensitivity, the specificity was 0.876 and the sensitivity was 0.662 for detection of rheumatoid arthritis. The ROC-AUC for the serum level of immunoglobulin M rheumatoid factor (RF) was 0.902. At a cutoff point of $19 \mathrm{U} / \mathrm{mL}$, the specificity was 0.955 and the sensitivity was 0.752 . The ROC-AUC for the serum level of anticyclic citrullinated peptide (CCP) antibody was 0.921 . At a cutoff point of $6.5 \mathrm{U} / \mathrm{mL}$, the specificity was 0.992 and the sensitivity was 0.828 .

analysis for the serum IL-13 level was 0.740. At a cutoff value of $0.7 \mathrm{pg} / \mathrm{mL}$, the specificity was 0.825 and the sensitivity was 0.676 . The ROC-AUC analysis for the serum IFN- $\gamma$ level was 0.656 . At a cutoff value of $1.8 \mathrm{pg} / \mathrm{mL}$, the specificity was 0.620 and the sensitivity was 0.655 . Taken together, these data suggest that the serum level of the sIL-18R $\alpha$ complex is better able to discriminate RA patients than the serum levels of IL-18, IL-13 or IFN- $\gamma$.
Tumor necrosis factor inhibitors decreased levels of soluble interleukin-18 receptor $\alpha$ in sera of rheumatoid arthritis patients

We treated 29 RA patients (2 males and 27 females; mean age $( \pm$ SEM), $56.7 \pm 2.8$ years $)$ with the TNF inhibitor etanercept ( $25 \mathrm{mg}$ once or twice weekly). Twentysix $(89.7 \%)$ or $15(51.7 \%)$ of 29 RA patients were treated with prednisolone $(6.27 \pm 0.63 \mathrm{mg} /$ day $)$ and/or methotrexate $(7.93 \pm 0.92 \mathrm{mg} /$ day $)$ in combination with 
etanercept. We evaluated the serum levels of sIL-18R $\alpha$, CRP, ESR, DAS28 (CRP), DAS28 (ESR) and HAQ score before and 6 months after treatment with etanercept. We observed significant $(P<0.0001)$ improvements in the serum levels of sIL-18R $\alpha$ complex, CRP, ESR, DAS28 (CRP), DAS28 (ESR) and HAQ score in the 29 RA patients (Figure 5).

\section{Discussion}

In this study, we have demonstrated the presence of the sIL-18R $\alpha$ chain in human serum. The sIL-18R $\alpha$ complex is composed of the soluble forms of the IL-18R $\alpha$ and IL-18R $\beta$ chains and IL-18. The complex was shown to bind to the surfaces of the human NK cell line NKO and prevented the production of IFN- $\gamma$ by NKO stimulated with IL-18 and IL-2 in vitro. Thus our results suggest that the sIL-18R $\alpha$ complex binds to the cell surface and attenuates IL-18 signaling.
A previous study showed that the molecular mass of IL-18R $\alpha$ protein isolated from the Hodgkin's disease cell line L428 was 64 to $100 \mathrm{kDa}$. The DNA sequence of hIL-18R $\alpha$ encodes the signal peptide (Met 1 to Ala 19) domains 1 through 3, to which IL-18 can bind (Glu 20 to Arg 329), and the transmembrane domain (Gly 330 to Tyr 351) [13]. The predicted molecular mass of the extracellular domain of the hIL-18R $\alpha$ chain is approximately $36 \mathrm{kDa}$. These results suggest that hIL-18R $\alpha$ protein on cell surfaces is highly glycosylated and shows sugar chain heterogeneity [13]. Our SDS-PAGE analysis using $\mathrm{CBB}$ staining showed that the sIL-18R $\alpha$ complex comprised a $50-\mathrm{kDa}$ major band and other bands of approximately 60 to 80,30 and $15 \mathrm{kDa}$. Western blot analysis showed that the IL-18R $\alpha$ protein associated with the IL-18R $\alpha$ complex had at least two components of approximately 50 and $30 \mathrm{kDa}$. As our anti-IL-18R $\alpha$ $\mathrm{mAb}(\mathrm{H} 44)$ recognizes the extracellular domain of

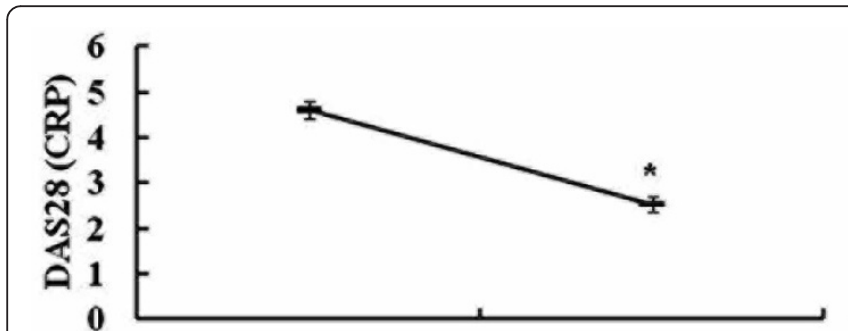

Baseline

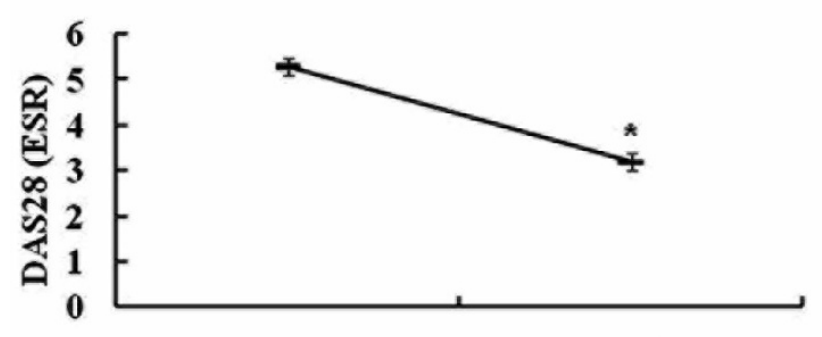

Baseline

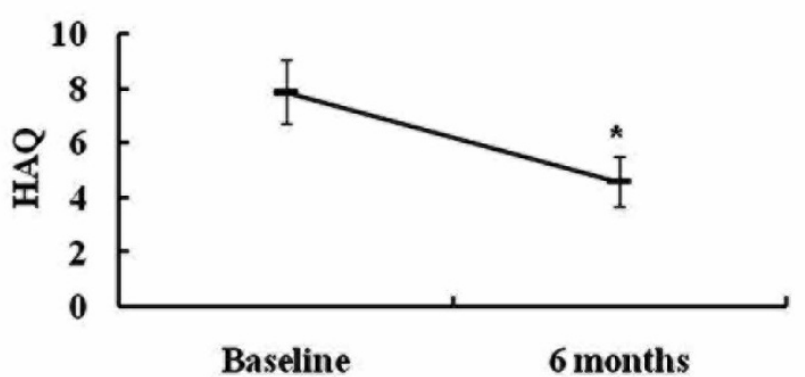

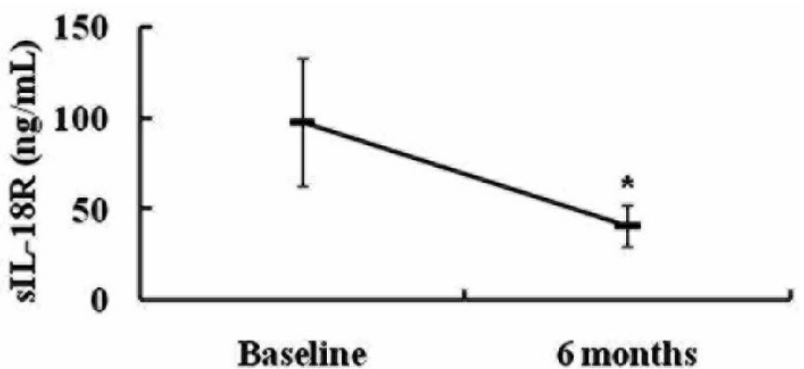
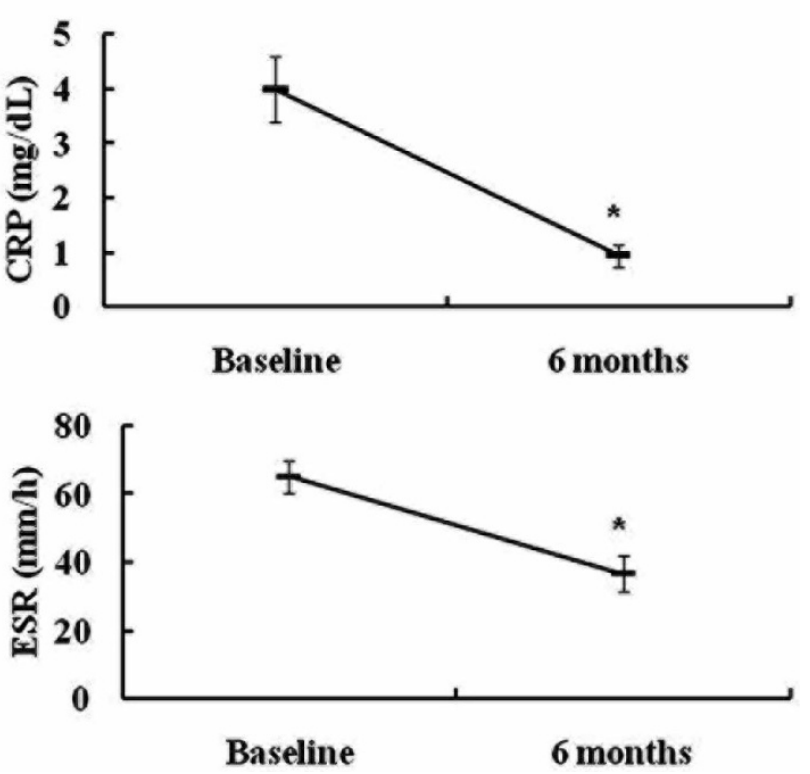

Figure 5 Tumor necrosis factor inhibitors decreased levels of soluble interleukin-18 receptor $\alpha$ in sera of rheumatoid arthritis patients. Twenty-nine rheumatoid arthritis patients (two males and twenty-seven females) were treated with the tumor necrosis factor inhibitor etanercept (25 mg once or twice weekly). The 28-joint Disease Activity Score (DAS28) (C-reactive protein (CRP) level), DAS28 (erythrocyte sedimentation rate (ESR)), Health Assessment Questionnaire (HAQ), soluble interleukin-18 receptor $\alpha$ complex in the sera, CRP level and ESR were evaluated before and 6 months after treatment with etanercept. ${ }^{*} P<0.05$ vs. baseline. 
hIL-18R $\alpha$ protein [30], the IL-18R $\alpha$ protein associated with the IL-18R $\alpha$ complex would have been derived from the extracellular domain of IL-18R $\alpha$. However, the molecular mass of the sIL-18R $\alpha$ protein associated with the IL-18R $\alpha$ complex was much smaller than that of the extracellular domain of hIL-18R $\alpha$ as reported previously on the cell surface $[13,30]$. Therefore, the sIL-18R $\alpha$ protein appears to be glycosylated or shows heterogeneity of its sugar chains.

Soluble cytokine receptors of the IL-1R/Toll-like receptor superfamily are thought to be generated by intramembrane proteolysis and/or alternative splicing. sIL-1RI is generated by the action of metalloprotease [5]. sIL-1RII can be generated by both proteolytic cleavage of receptor ectodomains and alternative splicing events. $\beta$-secretase 1 and $\beta$-secretase 2 can function as IL-1RII sheddases that cleave the IL-1RII ectodomain at a site adjacent to the $\alpha$-secretase site $[2,36]$. TNF- $\alpha-$ converting enzyme (ADAM17), a transmembrane metalloprotease, is also responsible for the proteolytic release or shedding of IL-1RII [37]. It has been reported that sIL-1RAcP is generated by alternative splicing rather than by ectodomain cleavage [38]. Therefore, the sIL$18 R \alpha$ chain seems to be generated by intramembrane proteolysis and/or alternative splicing events.

IL-18R $\beta$ shares structural similarities with IL-1RAcP [39]. Like sIL-1RAcP, a short form of the IL-18R $\beta$ (sIL18R $\beta$ mRNA transcript has been described in the rat [40], as well as in human and mouse [39]. A recent study showed that intravenous administration of adenoviruses encoding sIL-18R $\beta$ promoted collagen-induced arthritis in DBA/1 mice [39]. However, the biological function of sIL$18 R \beta$ is largely unknown. In the present study, we have shown that the sIL-18R $\alpha$ complex comprises IL-18 and sIL-18R $\alpha$ and sIL-18R $\beta$. Two different anti-IL-18R $\beta$ mAb clones, 132016 and 132029 (R\&D Systems, Inc.), detected bands of approximately 60,40 and $18 \mathrm{kDa}$ in the isolated sIL-18R $\alpha$ complex (data not shown). These two anti-IL$18 \mathrm{R} \beta \mathrm{mAbs}$ recognize the extracellular domain of the hIL$18 R \beta$ chain. Therefore, sIL-18R $\beta$ in human serum is likely derived from the extracellular domain of the hIL-18R $\beta$ chain generated by differential messenger RNA splicing.

It has been reported that the levels of various inflammatory cytokines and chemokines, such as IL-2, IL-4, IL-5, IL-6, IL-7, IL-10, IL-13, IFN- $\gamma$, granulocyte colonystimulating factor, granulocyte macrophage colonystimulating factor, monocyte chemotactic protein-1 and macrophage inflammatory protein- $1 \beta$, are increased in the sera of RA patients [41]. Inflammatory cytokines and chemokines, including IL-18, IL-13 and IFN- $\gamma$, may play an important role in the pathogenesis and development of RA $[8,9]$. In this study, we have shown that the serum levels of the IL-18R $\alpha$ complex in patients with RA or adult-onset Still's disease were significantly higher than those in healthy controls as well as in patients with OA or SLE. However, the origin of the IL- $18 R \alpha$ complex is still unclear. Therefore, we analyzed the levels of the sIL-18R $\alpha$ complex in both the synovial fluid and sera in three RA patients (26-, 39- and 81-year-old females). The levels of sIL-18R $\alpha$ complex in the synovial fluid in these RA patients were 22.1, 30.8 and $6.9 \mathrm{ng} /$ $\mathrm{mL}$, respectively. The levels of sIL-18R $\alpha$ complex in their sera were $39.8,23.6$ and $16.2 \mathrm{ng} / \mathrm{mL}$, respectively. Thus, the levels of sIL-18R $\alpha$ complex were not greatly increased in the synovial fluid in these three RA patients. Further analysis is needed to address the origin of the IL-18R $\alpha$ complex in RA patients.

ROC-AUC analysis revealed that RA patients could be discriminated by the serum level of the sIL-18R $\alpha$ complex as determined by ELISA. Moreover, the TNF inhibitor etanercept significantly decreased levels of sIL-18R $\alpha$ in the sera of 29 RA patients 6 months after the treatment. Thus, the sIL-18R $\alpha$ complex may play an important role in the inflammatory process of RA and adult-onset Still's disease. Our present results suggest that the level of the sIL-18R $\alpha$ complex in serum has potential clinical application as a biomarker for the diagnosis or differential diagnosis of RA or for the evaluation of disease activity in RA patients treated with TNF inhibitors.

\section{Conclusions}

In this study, we evaluated the levels and characteristics of the sIL-18R $\alpha$ complex in the sera of patients with RA and compared these to control populations. Our study indicates that sIL- $18 \mathrm{R} \alpha$ is present in the sera of RA patients and is complexed with IL-18 and IL-18R $\beta$. The levels detected by ELISA were substantially higher in the RA patients and patients with adult-onset Still's disease than in controls, and modeling using ROC-AUC analysis suggested that this assay might be of diagnostic value.

\section{Abbreviations}

BP: binding protein; CBB: Coomassie Brilliant Blue; IL: interleukin; IL-1RacP: IL-1 receptor accessory protein; IRA: interleukin 1-associated kinase; OA: osteoarthritis; PAGE: polyacrylamide gel electrophoresis; RA: rheumatoid arthritis; RF: rheumatoid factor; ROC-AUC: area under the receiver operating characteristic curve; SLE: systemic lupus erythematosus; TNF: tumor necrosis factor.

\section{Acknowledgements}

The authors thank Dr Howard A Young (National Cancer Institute, Frederick, MD, USA) for editing; Drs J Itoh (Chikugogawa-onsen Hospital, Ukiha, Japan), M Kawahara, H Koga (Keishinkai Hospital, Tosu, Japan) and Y Ohkubo (Chiwata Hospital, Nagasaki, Japan) for providing samples; Dr Tsukasa Seya (Hokkaido University, Sapporo, Japan) for providing rabbit antihuman IL-18Ro polyclonal antibody; and Dr Do-Young Yoon (Laboratory of Cellular Biology, Korea Research Institute of Bioscience and Biotechnology, Taejon, Korea) for providing antihuman IL-18 monoclonal antibody (clone 8). We also thank Ms Emiko Kuma, Ms Chie Ohki and Ms Kyoko Yamaguchi (Kurume University, Fukuoka Japan) for their technical assistance. This work was supported by a 
Grant-in-Aid for Scientific Research (C) (no. 21590977) (to TH) from the Ministry of Education, Science, Sports, and Culture of Japan; a grant to the Respiratory Failure Research Group from the Ministry of Health, Labor and Welfare, Japan (to HA); and by a grant from the Okamoto Satoshi Memorial Fund for Pulmonary Fibrosis Research (Tokyo, Japan) (to TH).

\section{Authors' contributions}

ST and TH performed the experiments, and performed the data analysis and data interpretation. ST, TH and HA drafted the manuscript. KM, YS, HO, ST, $\mathrm{HI}, \mathrm{TK}, \mathrm{SH}, \mathrm{HI}$ and TF collected samples. All authors read and approved the final manuscript.

\section{Competing interests}

TH holds a Japanese patent relating to sIL-18Ra complex (no. 4257946). All other authors declare that they have no competing interests.

Received: 24 September 2010 Revised: 23 February 2011

Accepted: 24 March 2011 Published: 24 March 2011

\section{References}

1. Sims JE: IL-1 and IL-18 receptors, and their extended family. Curr Opin Immunol 2002, 14:117-122.

2. Levine SJ: Mechanisms of soluble cytokine receptor generation. J Immunol 2004, 173:5343-5348.

3. Arend WP, Palmer G, Gabay C: IL-1, IL-18, and IL-33 families of cytokines. Immunol Rev 2008, 223:20-38

4. Slack J, McMahan CJ, Waugh S, Schooley K, Spriggs MK, Sims JE, Dower SK: Independent binding of interleukin-1 $\alpha$ and interleukin-1 $\beta$ to type I and type II interleukin-1 receptors. J Biol Chem 1993, 268:2513-2524.

5. Elzinga BM, Twomey C, Powell JC, Harte F, McCarthy JV: Interleukin-1 receptor type 1 is a substrate for $\gamma$-secretase-dependent regulated intramembrane proteolysis. J Biol Chem 2009, 284:1394-1409.

6. Hoshino T, Wiltrout RH, Young HA: IL-18 is a potent coinducer of IL-13 in NK and T cells: a new potential role for IL-18 in modulating the immune response. J Immunol 1999, 162:5070-5077.

7. Hoshino T, Yagita $H$, Ortaldo JR, Wiltrout $\mathrm{RH}$, Young $\mathrm{HA}$ : In vivo administration of IL-18 can induce lgE production through Th2 cytokine induction and up-regulation of CD40 ligand (CD154) expression on CD4 + T cells. Eur J Immunol 2000, 30:1998-2006.

8. Dinarello CA: Interleukin-18 and the pathogenesis of inflammatory diseases. Semin Nephrol 2007, 27:98-114.

9. Dinarello CA: Immunological and inflammatory functions of the interleukin-1 family. Annu Rev Immunol 2009, 27:519-550.

10. Hoshino T, Kato S, Oka N, Imaoka H, Kinoshita T, Takei S, Kitasato Y, Kawayama T, Imaizumi T, Yamada K, Young HA, Aizawa H: Pulmonary inflammation and emphysema: role of the cytokines IL-18 and IL-13. Am J Respir Crit Care Med 2007, 176:49-62.

11. Imaoka H, Hoshino $T$, Takei $S$, Kinoshita T, Okamoto M, Kawayama T, Kato S, Iwasaki H, Watanabe K, Aizawa H: Interleukin-18 production and pulmonary function in COPD. Eur Respir J 2008, 31:287-297.

12. Hoshino T, Okamoto M, Sakazaki Y, Kato S, Young HA, Aizawa H: Role of proinflammatory cytokines IL-18 and IL-1 $\beta$ in bleomycin-induced lung injury in humans and mice. Am J Respir Cell Mol Biol 2009, 41:661-670

13. Torigoe K, Ushio S, Okura T, Kobayashi S, Taniai M, Kunikata T, Murakami T, Sanou O, Kojima H, Fujii M, Ohta T, Ikeda M, Ikegami H, Kurimoto M: Purification and characterization of the human interleukin-18 receptor. J Biol Chem 1997, 272:25737-25742.

14. Hoshino K, Tsutsui H, Kawai T, Takeda K, Nakanishi K, Takeda Y, Akira S: Cutting edge: generation of IL-18 receptor-deficient mice: evidence for $\mathrm{IL}-1$ receptor-related protein as an essential IL-18 binding receptor. J Immunol 1999, 162:5041-5044

15. Cheung H, Chen NJ, Cao Z, Ono N, Ohashi PS, Yeh WC: Accessory proteinlike is essential for IL-18-mediated signaling. J Immunol 2005, 174:5351-5357.

16. Novick D, Kim SH, Fantuzzi $G$, Reznikov $L L$, Dinarello CA, Rubinstein $M$ : Interleukin-18 binding protein: a novel modulator of the Th1 cytokine response. Immunity 1999, 10:127-136.

17. Hayakawa H, Hayakawa M, Kume A, Tominaga S: Soluble ST2 blocks interleukin-33 signaling in allergic airway inflammation. J Biol Chem 2007, 282:26369-26380.
18. Kawashima M, Yamamura M, Taniai M, Yamauchi H, Tanimoto $T$ Kurimoto M, Miyawaki S, Amano T, Takeuchi T, Makino H: Levels of interleukin-18 and its binding inhibitors in the blood circulation of patients with adult-onset Still's disease. Arthritis Rheum 2001, 44:550-560.

19. Dai SM, Shan ZZ, Xu H, Nishioka K: Cellular targets of interleukin-18 in rheumatoid arthritis. Ann Rheum Dis 2007, 66:1411-1418.

20. Arnett FC, Edworthy SM, Bloch DA, McShane DJ, Fries JF, Cooper NS, Healey LA, Kaplan SR, Liang MH, Luthra HS, Medsger TA Jr, Mitchell DM, Neustadt DH, Pinals RS, Schaller JG, Sharp JT, Wilder RL, Hunder GG: The American Rheumatism Association 1987 revised criteria for the classification of rheumatoid arthritis. Arthritis Rheum 1988, 31:315-324.

21. Steinbrocker O, Traeger CH, Batterman RC: Therapeutic criteria in rheumatoid arthritis. J Am Med Assoc 1949, 140:659-662.

22. Prevoo ML, van 't Hof MA, Kuper $H H$, van Leeuwen MA, van de Putte LB, van Riel PL: Modified disease activity scores that include twenty-eightjoint counts: development and validation in a prospective longitudinal study of patients with rheumatoid arthritis. Arthritis Rheum 1995, 38:44-48.

23. Fries JF, Spitz P, Kraines RG, Holman HR: Measurement of patient outcome in arthritis. Arthritis Rheum 1980, 23:137-145.

24. Hoshino $T$, Ohta $A$, Yang D, Kawamoto M, Kikuchi M, Inoue $Y$, Kamizono $S$, Ota T, Itoh K, Oizumi K: Elevated serum interleukin 6, interferon- $\gamma$, and tumor necrosis factor-a levels in patients with adult Still's disease. J Rheumatol 1998, 25:396-398.

25. Yamaguchi M, Ohta A, Tsunematsu T, Kasukawa R, Mizushima Y, Kashiwagi H, Kashiwazaki S, Tanimoto K, Matsumoto Y, Ota T, et al: Preliminary criteria for classification of adult Still's disease. J Rheumatol 1992, 19:424-430.

26. Altman R, Asch E, Bloch D, Bole G, Borenstein D, Brandt K, Christy W, Cooke TD, Greenwald R, Hochberg M, Howell D, Kaplan D, Koopman W, Longley S III, Mankin H, McShane DJ, Medsger T Jr, Meenan R, Mikkelsen W, Moskowtiz R, Murphy W, Rothschild B, Segal M, Sokoloff L, Wolfe L: Development of criteria for the classification and reporting of osteoarthritis: classification of osteoarthritis of the knee. Diagnostic and Therapeutic Criteria Committee of the American Rheumatism Association. Arthritis Rheum 1986, 29:1039-1049.

27. Heinlen LD, McClain MT, Merrill J, Akbarali YW, Edgerton CC, Harley JB, James JA: Clinical criteria for systemic lupus erythematosus precede diagnosis, and associated autoantibodies are present before clinical symptoms. Arthritis Rheum 2007, 56:2344-2351.

28. Koizumi H, Sato-Matsumura KC, Nakamura H, Shida K, Kikkawa S, Matsumoto M, Toyoshima K, Seya T: Distribution of IL-18 and IL-18 receptor in human skin: various forms of IL-18 are produced in keratinocytes. Arch Dermatol Res 2001, 293:325-333.

29. Lee SJ, Cho YS, Cho MC, Shim JH, Lee KA, Ko KK, Choe YK, Park SN, Hoshino T, Kim S, Dinarello CA, Yoon DY: Both E6 and E7 oncoproteins of human papillomavirus 16 inhibit IL-18-induced IFN- $\gamma$ production in human peripheral blood mononuclear and NK cells. J Immunol 2001, 167:497-504

30. Kitasato $Y$, Hoshino T, Okamoto M, Kato S, Koda Y, Nagata N, Kinoshita M, Koga H, Yoon DY, Asao H, Ohmoto H, Koga T, Rikimaru T, Aizawa H: Enhanced expression of interleukin-18 and its receptor in idiopathic pulmonary fibrosis. Am J Respir Cell Mol Biol 2004, 31:619-625.

31. Hoshino T, Yamada A, Honda J, Imai Y, Nakao M, Inoue M, Sagawa K, Yokoyama MM, Oizumi K, Itoh K: Tissue-specific distribution and agedependent increase of human CD11b+ T cells. J Immunol 1993, 151:2237-2246.

32. Hoshino T, Kawase Y, Okamoto M, Yokota K, Yoshino K, Yamamura K, Miyazaki J, Young HA, Oizumi K: Cutting edge: IL-18-transgenic mice: in vivo evidence of a broad role for IL-18 in modulating immune function. $\mathrm{J}$ Immunol 2001, 166:7014-7018.

33. Toda R, Hoshino T, Kawayama T, Imaoka H, Sakazaki Y, Tsuda T, Takada S, Kinoshita M, Iwanaga T, Aizawa $\mathrm{H}$ : Validation of "lung age" measured by spirometry and handy electronic $\mathrm{FEV}_{1} / \mathrm{FEV}_{6}$ meter in pulmonary diseases. Intern Med 2009, 48:513-521.

34. Okamura H, Tsutsi H, Komatsu T, Yutsudo M, Hakura A, Tanimoto T, Torigoe K, Okura T, Nukada Y, Hattori K, Akita K, Namba M, Tanabe F, Konishi K, Fukuda S, Kurimoto M: Cloning of a new cytokine that induces IFN- $\gamma$ production by T cells. Nature 1995, 378:88-91.

35. Kim SH, Reznikov LL, Stuyt RJ, Selzman CH, Fantuzzi G, Hoshino T, Young HA, Dinarello CA: Functional reconstitution and regulation of IL-18 activity by the IL-18R $\beta$ chain. J Immunol 2001, 166:148-154. 
36. Levine SJ: Molecular mechanisms of soluble cytokine receptor generation. J Biol Chem 2008, 283:14177-14181.

37. Reddy P, Slack JL, Davis R, Cerretti DP, Kozlosky CJ, Blanton RA, Shows D, Peschon JJ, Black RA: Functional analysis of the domain structure of tumor necrosis factor-a converting enzyme. J Biol Chem 2000, 275:14608-14614.

38. Smith DE, Hanna R, Della F, Moore H, Chen H, Farese AM, MacVittie TJ, Virca GD, Sims JE: The soluble form of IL-1 receptor accessory protein enhances the ability of soluble type II IL-1 receptor to inhibit IL-1 action. Immunity 2003, 18:87-96.

39. Veenbergen $\mathrm{S}$, Smeets RL, Bennink MB, Arntz OJ, Joosten $L A$, van den Berg WB, van de Loo FA: The natural soluble form of IL-18 receptor $\beta$ exacerbates collagen-induced arthritis via modulation of T-cell immune responses. Ann Rheum Dis 2010, 69:276-283.

40. Andre R, Wheeler RD, Collins PD, Luheshi GN, Pickering-Brown S, Kimber I, Rothwell NJ, Pinteaux E: Identification of a truncated IL-18R 3 mRNA: a putative regulator of IL-18 expressed in rat brain. J Neuroimmunol 2003, 145:40-45.

41. Stabler T, Piette JC, Chevalier X, Marini-Portugal A, Kraus VB: Serum cytokine profiles in relapsing polychondritis suggest monocyte/ macrophage activation. Arthritis Rheum 2004, 50:3663-3667.

doi:10.1186/ar3295

Cite this article as: Takei et al:: Soluble interleukin-18 receptor complex is a novel biomarker in rheumatoid arthritis. Arthritis Research \& Therapy 2011 13:R52.

\section{Submit your next manuscript to BioMed Central} and take full advantage of:

- Convenient online submission

- Thorough peer review

- No space constraints or color figure charges

- Immediate publication on acceptance

- Inclusion in PubMed, CAS, Scopus and Google Scholar

- Research which is freely available for redistribution

Submit your manuscript at www.biomedcentral.com/submit 